\title{
Metformin inhibits the development and metastasis of ovarian cancer
}

\author{
BUCHU WU ${ }^{1}$, SHU LI $^{1}$, LILI SHENG $^{1}$, JING ZHU $^{1}$, LIYING GU $^{1}$, HAORAN SHEN $^{1}$, \\ DUANDUAN LA ${ }^{2}$, BRETT D. HAMBLY ${ }^{3}$, SHISAN BAO ${ }^{1,3}$ and WEN DI ${ }^{1}$ \\ ${ }^{1}$ Department of Obstetrics and Gynecology, Ren-Ji Hospital, ${ }^{2}$ Department of Obstetrics and Gynecology, Rui-Jin Hospital, \\ Shanghai Jiaotong University School of Medicine, Shanghai, P.R. China; ${ }^{3}$ Discipline of Pathology, \\ School of Medical Science and Bosch Institute, University of Sydney, Australia
}

Received February 17, 2012; Accepted April 3, 2012

DOI: $10.3892 /$ or.2012.1890

\begin{abstract}
The aim of this study was to investigate the role of metformin in the regulation of development and metastasis of ovarian carcinoma cell lines in vitro and ovarian cancer in a nude mouse model in vivo. The effects of metformin on the ability of two high-metastatic potential human ovarian cancer cell lines (SKOV3 and HO8910-PM) to adhere, invade and migrate in vitro were observed by means of a cell adhesion test, cell invasion test and cell migration test. The size and number of the inoculated and metastatic tumours in vivo in a nude mouse were determined following intraperitoneal injection of metformin. Furthermore, the extent of angiogenesis (vWF) and macrophage infiltration in the tumour were determined. Proliferation, migration, invasion and adhesion of ovarian cancer cells were significantly inhibited $(\mathrm{P}<0.05)$ in a dose-dependent manner in vitro. In addition, metformin inhibited hepatic, intestinal and lung metastasis $(\mathrm{P}<0.05)$, with no weight loss in vivo, consistent with decreased expression of vWF and macrophage infiltration. Our data suggest that metformin inhibits the development and metastasis of ovarian cancer by reducing cellular-ECM interactions, neovascularisation and macrophage infiltration.
\end{abstract}

\section{Introduction}

Ovarian carcinoma, the third highest morbidity among gynecological cancers, still has the highest mortality (1), despite current strategic management which has substantially improved the median survival rate over the past few decades. Two thirds of ovarian cancer patients have a low 5-year survival rate $(\sim 30 \%)$

Correspondence to: Dr Wen Di, Department of Obstetrics and Gynecology, Ren-Ji Hospital, Shanghai Jiaotong University School of Medicine, 1630 Dong Fang Rd, Shanghai 200127, P.R. China

E-mail: diwen163@163.com

Professor Shisan Bao, Discipline of Pathology, University of Sydney, NSW 2006, Australia

E-mail: bob.bao@sydney.edu.au

Key words: metformin, ovarian cancer, metastasis
(1), due to late diagnosis with peritoneal metastasis. The essential steps for metastasis include proliferation, adhesion to the peritoneum and migration into the stroma (2). Current management of ovarian cancer is cytoreductive surgery followed by chemotherapy (3), but yields an unsatisfactory prognosis.

Metformin has been used as an anti-hyperglycaemic drug for type-2 diabetes (4) with a safe tolerability profile, but also has a potential anti-tumour effect, since a significant reduction in the risk of malignancy has been observed in diabetic patients treated with metformin $(5,6)$. Metformin inhibits proliferation of breast (7), prostate (8), ovarian (9) and endometrium (10) malignant cells in vitro, which may be mediated via upregulation of AMPK activity (11). Furthermore, metformin significantly reduces growth of inoculated human p53-deficient breast cancer cells in nude mice (12), and reduces remission of breast cancer stem cells (13). However, it is still unclear if metformin can inhibit the growth and metastasis of ovarian cancer.

In this study, the ability of metformin to inhibit ovarian cancer, particularly adhesion, invasion and migration was studied in vitro was investigated. Furthermore, nude mice inoculated with the ovarian cancer cell line were evaluated by disease score, extent of neovascularisation and macrophage infiltration in the inoculated region, and location and extent of metastatic sites. These data support the clinical efficacy of metformin therapy for ovarian cancer and raise potential new lines of research investigating analogues of this drug for use as anti-cancer agents.

\section{Materials and methods}

Cell culture. Human ovarian SKOV3 and HO-8910PM cell lines with high-metastasis potential (14), obtained from Chinese Academy of Sciences, were cultured in RPMI-1640 medium (Gibco), supplemented with 10\% FBS (Gibco) using standard culture conditions (humidified $5 \% \mathrm{CO}_{2}$ at $37^{\circ} \mathrm{C}$ ).

Cell proliferation analysis. SKOV3 and HO-8910PM cell proliferation, following metformin (Sigma) treatment for 24, 48 or $72 \mathrm{~h}$, was assessed by Cell Counting kit-8 (CCK-8) (Dojindo). Briefly, $3 \times 10^{3}$ cells, seeded into 96-well plates, were treated with metformin $(0,1,5,10,20,50,100 \mathrm{mM})$. After 24,48 and $72 \mathrm{~h}$, $10 \mu \mathrm{l} \mathrm{CCK}-8$ was added to each well at $37^{\circ} \mathrm{C}$ for $2 \mathrm{~h}$. The supernatant absorbance $(450 \mathrm{~nm})$ from each well was measured, using 
MK3 micro-plate reader (Themo). The proliferation rate (\%) was calculated by comparing the absorbance of metformin-treated versus mock-treated cells.

Apoptosis analysis. Cell apoptosis was determined using an annexin V-FITC kit (KeyGen). Cells $\left(\sim 1 \times 10^{5}\right)$ were seeded in $6-\mathrm{cm}$ dishes and treated with metformin $(0,5,10$ and 20 $\mathrm{mM}$ ) for $24 \mathrm{~h}$ prior to analysis. The floating and adherent cells (trypsinized) were analysed with an EPICS-XL flow cytometer (Becton-Dickinson) after incubation with annexin V-FITC and PI at room temperature (RT) for $15 \mathrm{~min}$. Cells positive for early apoptosis (annexin V stained only) and for late apoptosis (annexin V and PI stained) were determined. Viable cells were negative for both annexin $\mathrm{V}$ and PI.

Adhesion analysis. Matrigel (BD Biosciences) dry-coated 96-well plates were blocked with $1 \%$ BSA for $1 \mathrm{~h}$. Metformin pretreated $(0,5,10,20 \mathrm{mM}$ for $24 \mathrm{~h})$ cells $\left(2 \times 10^{4}\right)$ were allowed to adhere to the coated well for $1 \mathrm{~h}$ at $37^{\circ} \mathrm{C}$, and the non-adherent cells were removed by 5 washings with cold PBS. The adherent cells in each well were measured using the CCK- 8 kit. The adhesion rate (\%) was calculated by comparing the adherent cell numbers following metformin versus mock treatment.

Invasion analysis. SKOV3 and HO-8910PM cells were collected by trypsinization and resuspended in serum-free medium $\left(3 \times 10^{5} /\right.$ $\mathrm{ml})$. Cells $\left(1 \times 10^{5} / \mathrm{ml}\right)$ in serum-free medium were placed into the upper wells, coated with $50 \mu \mathrm{l}$ of Matrigel (1:6 dilution) of the Boyden chamber ( $8 \mu \mathrm{m}$ pore size, Millipore) with metformin $(0,5,10$ and $20 \mathrm{mM})$. Medium containing $20 \%$ FBS was added to the lower chamber. Cell invasion into the Matrigel was determined following $24 \mathrm{~h}$ under standard culture conditions. The membrane containing invading cells was methanol fixed and $\mathrm{H} \& \mathrm{E}$ stained, after removing non-invading cells on the upper side of the membrane with cotton swabs.

Migration analysis. Cell migration was determined using a wound-healing motility assay (2). SKOV3 and HO-8910PM cells $\left(4 \times 10^{4}\right)$ were added to a 6 -well plate with metformin $(0,5,10$ and $20 \mathrm{mM}$ ) and incubated for $24 \mathrm{~h}$. After scratching with a plastic cell scraper of fixed width, the monolayer of cells was washed 3 times with PBS to remove the detached cells. The remaining adherent cells were incubated using standard culture conditions. Cell migration was determined by monitoring reduction in the width of the scaped zone at various time-points for up to $18 \mathrm{~h}$, to avoid cell doubling (average doubling time $\sim 22 \mathrm{~h}$ ). The migration rate (\%) was calculated from the migration distance at different dosages compared to mock-treatment.

Metastasis assay in vivo. Five-weeks old female athymic BALB/c nude mice, obtained from the Chinese Academy of Sciences (15), were housed under conventional laboratory conditions with chow and water available ad libitum. Experiments adhered to the guidelines of the Shanghai Jiaotong University, Animal Ethics Committee. Nude mice were inoculated on their back with $2 \times 10^{6} \mathrm{HO}-8910 \mathrm{PM}$ cells in $100 \mu \mathrm{l}$ of PBS, to establish a viable solid tumour. The established tumour was dissected into $1 \mathrm{~mm}^{3}$ pieces and one piece was implanted orthotopically on the right ovarian capsule of the recipient nude mouse. A total of 14 female nude mice (5-weeks old) were randomly divided into 2 groups.
Two weeks post-implantation, metformin (Glucophage, Squibb, $250 \mathrm{mg} / \mathrm{kg}$ body weight) in normal saline (NS), was administered i.p. every other day for 4 weeks in the metformin-treated group, whereas the mock-treated group received NS only. The disease score was calculated by adding body weight, activity and responsiveness, mobility, ascites and gross tumour size together (16). The sizes of the inoculated and metastatic tumours were determined by mean tumour volume $\left[\mathrm{MTV}=\mathrm{XY}^{2} / 2\right.$, where $\mathrm{X}$ is the shorter and $\mathrm{Y}$ is the longer diameter $(\mathrm{mm})$ of orthogonal measurements] (15), after sacrificing the mice at 8 weeks postimplantation. Histopathology of the original and metastatic tumours was performed in formalin-fixed, wax-embedded and H\&E-stained sections $(5 \mu \mathrm{m})$.

Immunohistochemistry analysis. Paraffin sections $(5 \mu \mathrm{m})$ were incubated with rat anti-F4/80 (WEHI) or vWF (Dako) antibodies followed by a horseradish peroxidise-conjugated rabbit anti-rat antibody (Dako), as described (17). All sections were then visualized with 3,3'-diaminobenzidine (Dako), and lightly counterstained with hematoxylin. Immunohistochemical quantifications were performed on digitized images using image analysis software Image-Pro Plus. The presence of monocytes/ macrophages was assessed using anti-F4/80 antibody and the proportion of positive cells was determined by [100\% x (number of positive nuclei/total number of nuclei)].

Statistical analyses. Each experiment was done in triplicate. All data are expressed as means \pm standard error or division of the mean (SEM or SD). Data analysis was carried out by one-way and two-way ANOVA using GraphPad Prism 4.0. P<0.05 was considered statistically significant.

\section{Results}

Metformin inhibits proliferation of human ovarian cancer cells. Metformin inhibited the proliferation of SKOV3 cells in a dose-dependent manner $(0-100 \mathrm{mM})$ at 24,48 and $72 \mathrm{~h}$ in vitro (Fig. 1A). Significantly greater inhibition of proliferation of SKOV3 cells was observed following 48- and 72-h metformintreatment in the range $5-50 \mathrm{mM}$, compared to $24-\mathrm{h}$ treatment. The inhibition at 48 or $72 \mathrm{~h}$ reached plateau at $25 \mathrm{mM}$ dose. A similar pattern was observed in HO-8910PM cells following metformin-treatment, but a significant difference between $24 \mathrm{~h}$ and $48 / 72 \mathrm{~h}$ was observed at $5 \mathrm{mM}$ only (Fig. 1B). To evaluate whether the metformin-induced reduction in proliferation was due to apoptosis, cells were assessed for annexin $\mathrm{V}$ expression using flow cytometry. No apoptosis was detected in SKOV3 cells following 24-h metformin-treatment $(0-20 \mathrm{mM})$ (Fig. 1C-F). The $\mathrm{IC}_{50}$ for metformin for SKOV3 or HO-8910PM cells was 20.62 or $16.67 \mathrm{mM}$ over $24 \mathrm{~h}$, respectively $(\mathrm{P}<0.01)$.

Metformin inhibits adhesion, invasion and migration of human ovarian cancer cell lines. Metformin significantly inhibited SKOV3 and HO-8910PM cell adhesion in a dose-dependent manner, by $\sim 50 \%$ at the $\mathrm{IC}_{50}(20 \mathrm{mM})$, compared to the mocktreated groups (Fig. 2A). Metformin-treatment $(0-20 \mathrm{mM})$ resulted in a remarkable dose-dependent decline in the invasive ability of the ovarian cancer cells, $\sim 60 \%$ and $\sim 40 \%$ in SKOV3 and HO-8910PM cells, respectively, at the $\mathrm{IC}_{50}$ of $20 \mathrm{mM}$ (Fig. 2B). Furthermore, metformin significantly inhibited the migration 
SKOV3

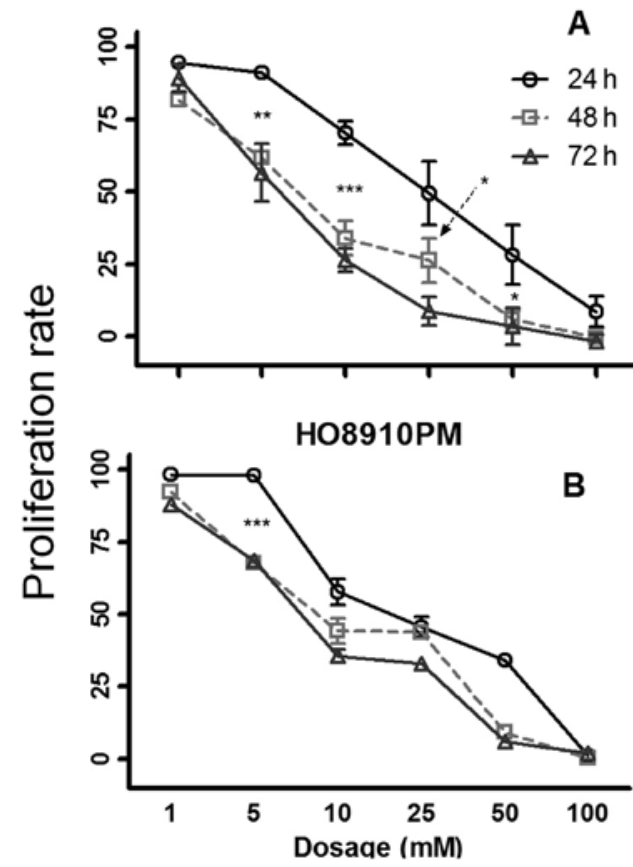

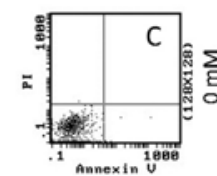
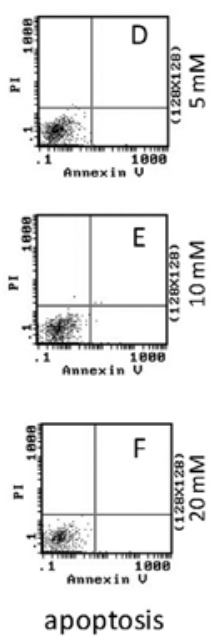

Figure 1. Proliferation rate of SKOV3 (A) and HO-8910PM cells (B) following metformin-treatment at 24,48 and $72 \mathrm{~h}$. Mean \pm SEM. ${ }^{*} \mathrm{P}<0.05,{ }^{* *} \mathrm{P}<0.01$, ${ }^{* * *} \mathrm{P}<0.001$. Apoptosis of SKOV3 cells was determined using flow cytometry analysis following metformin for different dosages [(C), $0 \mathrm{mM}$; (D), $5 \mathrm{mM}$; (E), $10 \mathrm{mM}$; and (F), $20 \mathrm{mM}$ ] for $24 \mathrm{~h}$.

in SKOV3 and HO-8910PM cells in a dose-dependent manner (Fig. 2C), reaching $\sim 80 \%$ inhibition at $20 \mathrm{mM}$ concentration.

Metformin inhibits ovarian cancer growth and metastasis in vivo. All mice developed bloody ascites two weeks postorthotopic tumour implantation, in both the metformin (250 mg/kg) and mock-treated groups (Fig. 3A and B). One mouse died due to extreme cachexia in the mock-treated group at 6 weeks after implantation; whereas all 7 mice survived in the metformin-treated group. The size of the orthotopic implanted ovarian cancer increased substantially in both metformin and mock-treated groups (black arrow, Fig. 3C and D). No significant difference in the size of the orthotopic tumour was observed between these two groups [2095 $\pm 768.2 \mathrm{~mm}^{3}$ (7 mice) vs $2728 \pm 987.5 \mathrm{~mm}^{3}$ (6 mice), metformin vs mock-treatment].

The extent of metastases was greater in the mock-treated group compared to the metformin-treated group. There were peritoneal macroscopic metastases (liver, intestine, spleen and pancreas) (white arrows, Fig. 3D) in all mock-treated mice (6/6). The sites of metastasis were the peritoneum $(5 / 6)$, contra-lateral ovary $(3 / 6)$, mesentery $(2 / 6)$, intestine $(5 / 6)$, liver $(4 / 6)$, kidney $(1 / 6)$, spleen $(1 / 6)$, diaphragm (3/6), and mesenteric lymph nodes (1/6). By contrast, in the metformin-treated group, fewer metastases were detected; to the peritoneum (2/7), intestine (4/7) and mesentery (2/7). The number and size of the intestinal metastases was noted to be fewer and smaller than that of the mock-treated group (Fig. 3C and D).

A trend towards decreased body weight in the mock-treatment mice was observed over 35 days, due to cachexia; whereas there was slight body weight gain in the metformin-treatment
A
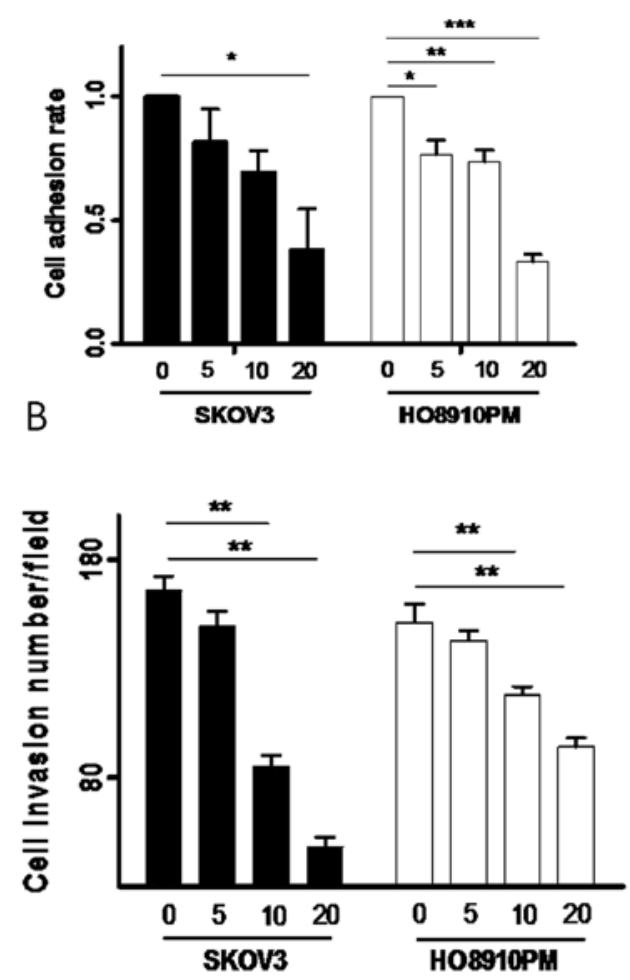

C

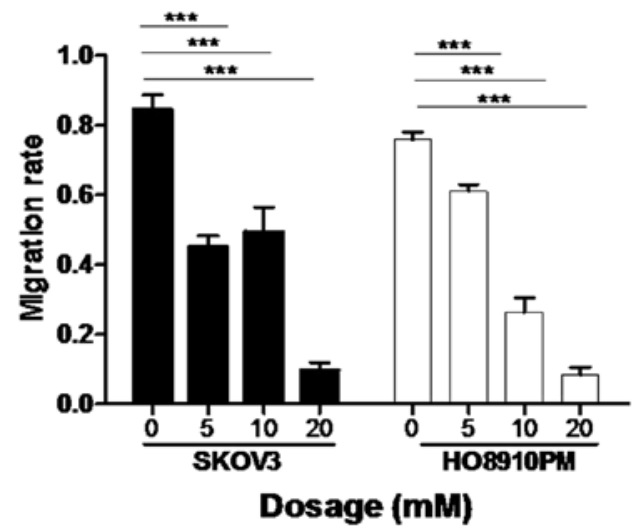

Figure 2. Cellular adhesion (A), invasion (B) and migration (C) of SKOV3 or HO-8910PM cells was inhibited by metformin at different dosages. Mean \pm SEM. ${ }^{*} \mathrm{P}<0.05,{ }^{* *} \mathrm{P}<0.01,{ }^{* * *} \mathrm{P}<0.001$.

mice during the same period. No significant difference in body weight was observed between the mock and metformin-treated groups (Fig. 3E). The disease score was $>1.5$-fold higher in the mock-treatment group compared to the metformin-treated group at 8 weeks post-orthotopic implantation $(\mathrm{P}<0.01)($ Fig. $3 \mathrm{~F})$.

Histopathological analysis. The orthotopic tumours demonstrated similar histopathological features to malignant papillary serous adenocarcinoma of the ovary (Fig. 4A and B). Microscopic, but not macroscopic, metastatic lesions were observed in the lungs of mock-treated animals (arrow, Fig. 4D), but not in the metformin-treated mice (Fig. 4C). There were metastatic lesions detected in the intestine from both mock- and metformin-treated animals (Fig. 4E and F). Deeper invasive lesions were detected in the mock-treated group (through the muscularis propria to the 

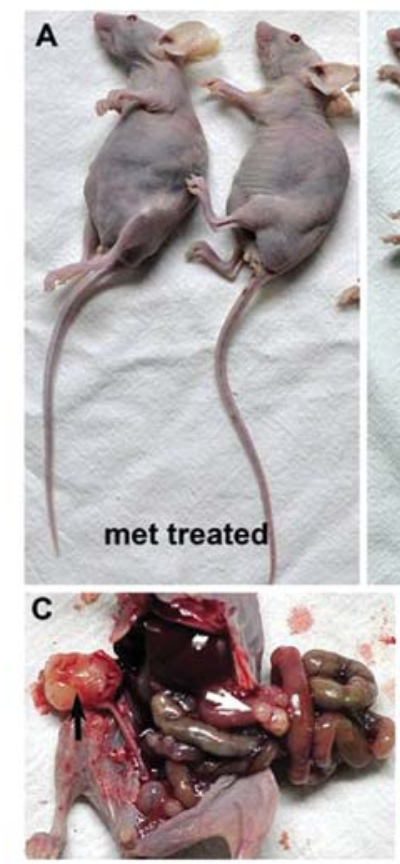

E Body weight change

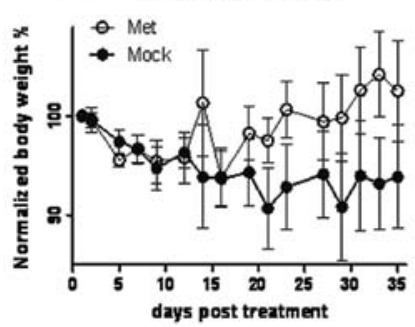

Figure 3. The metastasis of HO-8910PM ovarian cancer cells inoculated in nude mice following metformin (A and C) or mock-treatment (B and D). Inoculated ovarian tumour (black arrow) metastasised to intestine, liver, spleen and peritoneum (white arrows). Fewer and smaller metastases were observed in the metformin-treated group (C versus $\mathrm{D})$. The body weight change of the mice (\% of baseline) following either metformin or mock-treatment (E), showed no significant difference. Significantly higher disease score (1.5-fold) was observed in the mock-treated compared to the metformin-treated group $(\mathrm{P}<0.01)(\mathrm{F})$.

mucosa, white arrow, Fig. 4F), compared to the metformin-treated group (limited to the serosa, white arrow, Fig. 4E). There were metastatic lesions in the liver from the mock-treated mice (arrow, Fig. $4 \mathrm{H}$ ), while no liver metastasis was detected in the livers from the metformin-treated animals (Fig. 4G), suggesting that inability to penetrate the muscularis propria in the metformintreated group inhibited portal venous metastasis. Larger capsular metastases were observed on the spleen from the mock-treated animals (arrow, Fig. 4J) compared to the smaller splenic capsular metastases in the metformin-treated group (Fig. 4I). No directly attached metastatic lesions were observed on the kidney (Fig. $4 \mathrm{~K}$ and $\mathrm{L}$ ) or the uterus (Fig. 4M and N) from both mock- and metformin-treated groups.

Metformin decreases tumour neovascularisation and macrophage infiltration. Using immunohistochemistry, metformin was found to inhibit neovascularisation (vWF expression), in intestinal and hepatic metastases. vWF expression in the gut and liver from the metformin-treated group was $\sim 75 \%(\mathrm{P}<0.001)$ and $\sim 40 \%(\mathrm{P}<0.05)$ lower than the mock-treated group, respectively

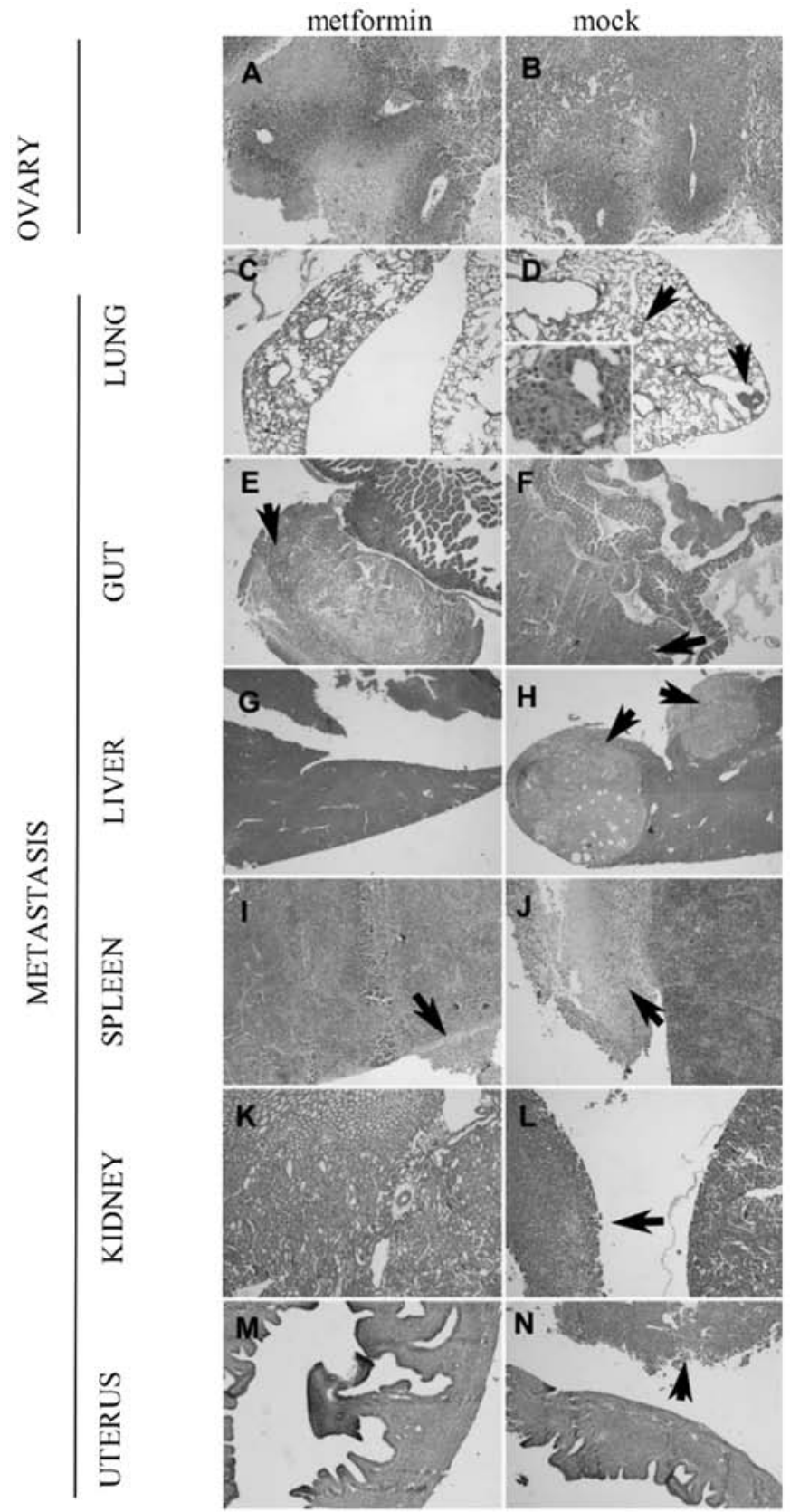

Figure 4. Histopathology of metformin and mock-treated groups from HO-8910PM inoculated ovarian tumour. The slides were stained with hematoxylin and eosin and visualized at $\mathrm{x} 4$ or $\mathrm{x} 10$. Histology of the inoculated ovarian tumour showed malignant papillary serous adenocarcinoma (A and B). Tumour cells (black arrows) metastasized to the lung (C and D), intestine (E and F), liver $(\mathrm{G}$ and $\mathrm{H})$, spleen (I and $\mathrm{J})$, kidney (K and $\mathrm{L}$ ) and uterus ( $\mathrm{M}$ and $\mathrm{N}$ ).

(Fig. 5A-F). Inhibition of macrophage infiltration was also observed in the metformin group, compared to the mock-treatment group, in the lung ( 60\%) and the liver ( 90\%) (Fig. 5A-F).

\section{Discussion}

The rationale for our current experiment is based on reports that metformin possesses anti-tumour capabilities (8-11). The current standard therapy for ovarian cancer is combined chemotherapy following surgery. However, development of drug-resistance and other side effects compromise the effects of chemotherapy. 

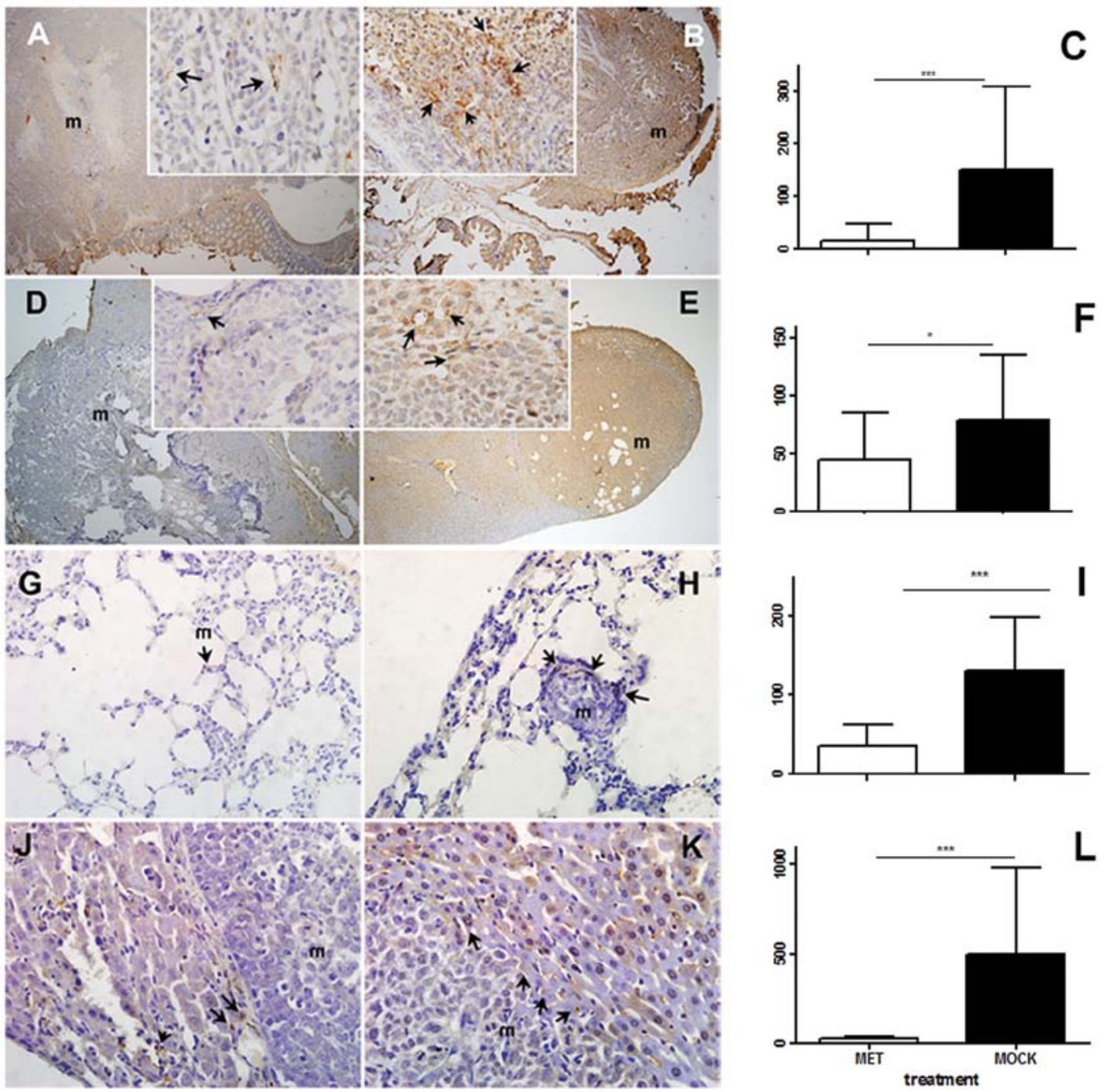

Figure 5. Immunohistochemistry of vWF expression and macrophage infiltrations (black arrows) in inoculated and metastatic sites following metfomin or mocktreatment. The expression of vWF was significantly decreased in the intestine $(\mathrm{A}-\mathrm{C})$ and liver $(\mathrm{D}-\mathrm{F})$ following metformin versus mock-treatment $(\mathrm{P}<0.001)$. The number of macrophages was significantly decreased in the lung $(\mathrm{G}, \mathrm{H}$ and $\mathrm{I})$ and liver $(\mathrm{J}$-L) following metformin versus mock-treatment $(\mathrm{P}<0.001)$. $\mathrm{m}$, metastasis.

Metformin is an anti-hyperglycemia drug in use for over 60 years with few adverse effects (4). Our study demonstrated that metformin inhibited proliferation, adhesion, invasion and migration in human epithelial ovarian cancers (HO-8910PM and SKOV3 cell lines) in vitro, in a dose- and time-dependent manner. Furthermore, metformin inhibited growth and metastasis of these ovarian cancers in vivo in a nude mouse model.

Effective inhibition of SKOV3 cell proliferation in vitro occurred at an $\mathrm{IC}_{50}$ of $\sim 20 \mathrm{mM}$ metformin, without necrosis or apoptosis in these cells. These data suggest that this dose has no direct cytotoxicity, suggesting that this dose is at a therapeutic level. This is consistent with findings in breast and prostate cancer cell lines following metformin-treatment, where no cell death was observed, but tumour cells were arrested at the G0/ G1 stage $(7,8)$.

Our data are the first to demonstrate that metformin inhibits growth and metastasis of ovarian cancer in vivo, in a nudemouse model. Previous reports have shown that metformin inhibited growth of inoculated breast cancer cells in nude mice, especially in a p53-deficient- (12) and in an ER $\alpha^{-}$MDA-MB-435 human breast cancer cell line (18). Interestingly, the dosages of metformin chosen for the breast cancer experiments were 2- and 6-fold higher, respectively, than that used in the present study. The dosage chosen in the present study was based on the recommended maximal therapeutic daily dose in human, i.e., $2,550 \mathrm{mg} / 60 \mathrm{~kg}$. The dosage differences may be due to the different forms of cancer, and/or may reflect different therapeutic pathways. The precise underlying mechanisms are worthy of further investigation.

A non-significant trend towards body-weight loss in the mock-treated, compared to the metformin-treated, group was observed. However, the overall condition of the mice was more accurately quantified by the disease score, which was found to be higher in the mock-treated group, consistent with metformin acting as an effective anti-cancer therapy. The failure to observe a significant difference in body-weight between the metforminand mock-treated groups may be due to greater ascites generation during the growth and metastasis of ovarian cancer in the mock-treatment group. Qualitatively, more severe cachexia was observed in the mock-treated group.

Angiogenesis is another objective factor predicting prognosis for overall and disease-free survival in advanced ovarian cancer 
(19). We showed reduced expression of vWF, reflecting decreased neovascularisation, in metastatic tissues following metformintreatment, compared to mock-treatment. The suppressed vWF level correlates well with reduced size and number of metastases.

Macrophages contribute to tumour dissemination by upregulating tumour cell adhesion molecules, releasing invasive proteases and promoting angiogenesis $(20,21)$. We showed metformin significantly suppressed macrophage infiltration in metastatic tissues compared with mock-treatment, correlating with the reduced size and number of liver and lung metastasis. Thus, macrophage-mediated metastasis appears to play an important role in dissemination of ovarian cancer, which may also be a useful target for future therapeutic intervention. In conclusion, metformin inhibits growth and metastasis of ovarian cancer, by down-regulating pFAK and MMP-2 observed in vitro, and by reduction of macrophage infiltration and $\mathrm{vWF}$ expression observed in vivo. Future experiments will focus on the underlying mechanism/s of the anti-tumour effects of metformin, and its potential to move forward into clinical application for the management of ovarian cancer.

\section{Acknowledgements}

This study was supported by grants from Hundred Talent program, Shanghai Jiaotong University School of Medicine; Overseas Exchange PhD Fellowship, Shanghai Jiaotong University; The Bureau of Science and Technology; Shanghai Municipal (08XD14027); the National Natural Science Foundation (30772306), and an Award of Outstanding Young Academics Foundation of Shanghai Universities (JDY08042). The authors acknowledge assistance from the Histopathology Laboratory, The Discipline of Pathology, The University of Sydney.

\section{References}

1. Jemal A, Siegel R, Ward E, Hao Y, Xu J and Thun MJ: Cancer statistics, 2009. CA Cancer J Clin 59: 225-249, 2009.

2. Zhang J and Wang B: Arsenic trioxide (As(2)O(3)) inhibits peritoneal invasion of ovarian carcinoma cells in vitro and in vivo. Gynecol Oncol 103: 199-206, 2006.

3. Gubbels JA, Claussen N, Kapur AK, Connor JP and Patankar MS The detection, treatment, and biology of epithelial ovarian cancer. J Ovarian Res 3: 8, 2010.

4. Bailey CJ and Turner RC: Metformin. N Engl J Med 334: 574-579, 1996.
5. Evans JM, Donnelly LA, Emslie-Smith AM, Alessi DR and Morris AD: Metformin and reduced risk of cancer in diabetic patients. BMJ 330: 1304-1305, 2005.

6. Libby G, Donnelly LA, Donnan PT, Alessi DR, Morris AD and Evans JM: New users of metformin are at low risk of incident cancer: a cohort study among people with type 2 diabetes. Diabetes Care 32: 1620-1625, 2009.

7. Zhuang Y and Miskimins WK: Cell cycle arrest in Metformin treated breast cancer cells involves activation of AMPK, downregulation of cyclin D1, and requires $\mathrm{p} 27^{\mathrm{Kipl}}$ or $\mathrm{p} 21^{\mathrm{Cipl}}$. J Mol Signal 3: 18,2008

8. Ben Sahra I, Laurent K, Loubat A, et al: The antidiabetic drug metformin exerts an antitumoral effect in vitro and in vivo through a decrease of cyclin D1 level. Oncogene 27: 3576-3586, 2008.

9. Gotlieb WH, Saumet J, Beauchamp MC, et al: In vitro metformin anti-neoplastic activity in epithelial ovarian cancer. Gynecol Oncol 110: 246-250, 2008.

10. Cantrell LA, Zhou C, Mendivil A, Malloy KM, Gehrig PA and Bae-Jump VL: Metformin is a potent inhibitor of endometrial cancer cell proliferation - implications for a novel treatment strategy. Gynecol Oncol 116: 92-98, 2010.

11. Zakikhani M, Dowling R, Fantus IG, Sonenberg N and Pollak M: Metformin is an AMP kinase-dependent growth inhibitor for breast cancer cells. Cancer Res 66: 10269-10273, 2006.

12. Buzzai M, Jones RG, Amaravadi RK, et al: Systemic treatment with the antidiabetic drug metformin selectively impairs p53-deficient tumor cell growth. Cancer Res 67: 6745-6752, 2007.

13. Hirsch HA, Iliopoulos D, Tsichlis PN and Struhl K: Metformin selectively targets cancer stem cells, and acts together with chemotherapy to block tumor growth and prolong remission. Cancer Res 69: 7507-7511, 2009.

14. Shenhua X,Lijuan Q,Hanzhou N, et al: Establishment of a highly metastatic human ovarian cancer cell line (HO-8910PM) and its characterization. J Exp Clin Cancer Res 18: 233-239, 1999.

15. Zhang S, Lin QD and Di W: Suppression of human ovarian carcinoma metastasis by the metastasis-suppressor gene, BRMS1. Int J Gynecol Cancer 16: 522-531, 2006.

16. Bao S, Carr ED, Xu YH and Hunt NH: Gp91(phox) contributes to the development of experimental inflammatory bowel disease. Immunol Cell Biol 89: 853-860, 2011.

17. $\mathrm{Xu} \mathrm{Y,} \mathrm{Hunt} \mathrm{NH}$ and Bao S: The role of granulocyte macrophage-colony-stimulating factor in acute intestinal inflammation. Cell Res 18: 1220-1229, 2008

18. Phoenix KN, Vumbaca F and Claffey KP: Therapeutic metformin/ AMPK activation promotes the angiogenic phenotype in the ERalpha negative MDA-MB-435 breast cancer model. Breast Cancer Res Treat 113: 101-111, 2009.

19. Brem S, Cotran R and Folkman J: Tumor angiogenesis: a quantitative method for histologic grading. J Natl Cancer Inst 48: 347-356, 1972.

20. Jonjic N, Peri G, Bernasconi S, et al: Expression of adhesion molecules and chemotactic cytokines in cultured human mesothelial cells. J Exp Med 176: 1165-1174, 1992.

21. Coussens LM and Werb Z: Inflammation and cancer. Nature 420: $860-867,2002$ 